\title{
Automatic Tracking System of Solar Panel Based on Single Chip Microcomputer
}

\author{
Danping Jia and Yang Wang ${ }^{*}$ \\ Shenyang University of Technology, 110870, China \\ ${ }^{*}$ Corresponding author
}

\begin{abstract}
In order to improve the utilization rate of solar energy, A STC89C52 SCM to control the core of solar panel automatic tracking system is designed in this paper. It adopts the method of photoelectric tracking and sun angle tracking. The system judges sunny or cloudy by the weather detection circuit. When it is sunny day, the system uses the photoelectric sensor to gather the light intensity deviation to control the stepper motor to realize the photoelectric tracking. When it is cloudy day, the system can calculate the local solar altitude angle and azimuth angle by collecting the information of the clock chip, and the single chip microcomputer can drive the stepper motor through the instruction to realize the sun angle tracking. The experimental results show that the solar tracking system can track the sun in different weather conditions, and the energy receiving efficiency is improved obviously.
\end{abstract}

Keywords-photoelectric detection; sun angle; automatic tracking; single chip microcomputer

\section{INTRODUCTION}

In recent years, the application of solar energy has become increasingly widespread, such as solar water heater, solar power generation, desalination, solar hydrogen and so on [1].However, the solar density is low, intermittent, changing the spatial distribution of the characteristics of the sun's precise tracking put forward higher requirements. Currently tracking the sun can be summarized in two ways: photoelectric tracking and sun angle tracking [2].Photoelectric tracking method has high sensitivity and convenient structure design, but it is greatly affected by light intensity and weather. While the sun angle tracking method has the advantage of all-weather real-time tracking, but the program is complex, its power consumption is large, and the lack of severe weather conditions of the protection function [3].These two methods have their own advantages, but also have their own disadvantages. Therefore, this paper will design a set of solar panel automatic tracking system of photoelectric tracking and sun angle tracking mode combination. The system can not only maintain high sensitivity, but also can be suitable for more complex weather environment, effectively improve the utilization of solar energy, has a good prospect for development and promotion of value.

\section{The Overall Design of The System}

The system mainly consists of photoelectric detection module, A/D conversion module, SCM, driver module, weather detection module, clock module, solar panels and other components. The overall block diagram of the system is shown in Figure I.

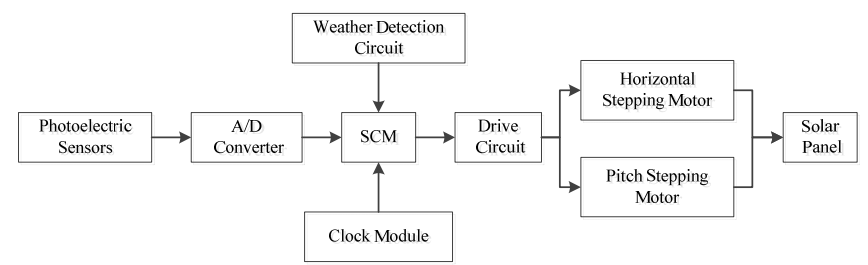

FIGURE I. THE OVERALL BLOCK DIAGRAM OF THE SYSTEM

The general workflow is like this, after the boot, the system detects whether it is day or night, when the system detects the night, then the system stops running. If the system detects daylight, then the system further detects for sunny or cloudy. In the sunny day, the system adopts the photoelectric detection method. When it is cloudy day, the system adopts the sun angle tracking method. The combination and complementation of these two tracking methods make the system running more stable and improve the accuracy of tracking system.

\section{HARDWARE DESIGN}

\section{A. Weather Detection Circuit}

The weather detection circuit uses photosensitive resistance as a photoelectric element, the use of its resistance to change with the intensity of light characteristics, and operational amplifier composition circuit. The output of the amplifier connected with the single chip microcomputer P1.7, LM324's inverting input connected to the fixed voltage, LM324 in-phase input terminal of photosensitive resistance. Through the test to determine the photosensitive resistor R1 model GL5528, R2=4.7k, R3=1k. The weather detection circuit is shown in Figure II.

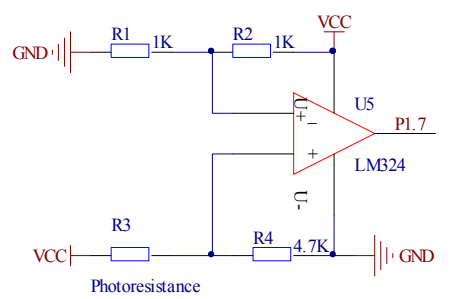

FIGURE II. THE WEATHER DETECTION CIRCUIT

When the weather is cloudy, the light intensity is weak, the resistance of the larger photosensitive resistance, about 
$45 \mathrm{k}$. The non-inverting input of the operational amplifier is lower than the potential of the inverting input, and the output of the operational amplifier will output a low level. The P1.7 port of the single chip microcomputer can detect a low level, and then by the follow-up circuit and program control system to convert the sun angle tracking mode.

When the weather is sunny, the light intensity is strong, the intensity of sunlight to the photosensitive resistor decreases, about $1 \mathrm{k}$.The non-inverting input of the operational amplifier is higher than the inverting input, and the output of the operational amplifier will output a high level. The P1.7 port of the single chip microcomputer can detect a high level, and then by the follow-up circuit and program control, making the program can continue to run, and then continue to use photoelectric tracking mode.

\section{B. Photoelectric Detection Module}

The photoelectric detection module uses the principle that the resistance changes when the light-sensitive resistor receives the light to detect whether the sunlight is irradiated on the solar panel vertically [4].The basic structure of photoelectric detection module is shown in Figure III.

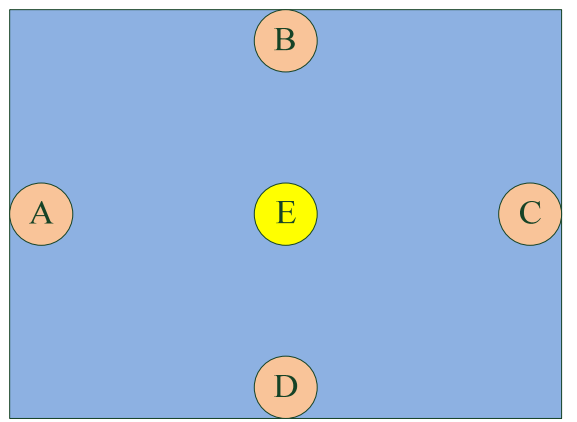

FIGURE III. THE BASIC STRUCTURE OF PHOTOELECTRIC DETECTION MODULE

As shown in Figure III, the four-way photosensitive resistances were arranged in a crisscross pattern, located in the center of the photosensitive resistor to determine the cloudy or sunny [5].When the sunlight is irradiated vertically on the solar panel, the light intensity of the four photosensitive resistances is almost the same. As time goes by, the sunlight will gradually deviate from the center position, resulting in exposure to each photosensitive resistor on the light intensity changes, so its resistance changes, namely the voltage across the photosensitive resistance also changes single chip microcomputer reads the voltage across the four photosensitive resistances and compares the voltage value with the analysis. When the voltage difference between the two ends of the upper and lower, the left and right of the photosensitive resistance is more than $0.2 \mathrm{~V}$, the single chip microcomputer will drive the stepper motor rotation to be adjusted until the voltage difference between the two ends of the upper and lower, the left and right of the photosensitive resistance is less than $0.2 \mathrm{~V}$.

\section{Drive Module}

This design uses ULN2803 as a stepper motor drive components, because the output power of the single chip microcomputer is too small, can not be directly applied to the stepper motor drive circuit [6].ULN2803 is the eight NPN Darlington transistor array series connection, and It is particularly applicable to low logic level digital circuits (such as TTL, CMOS or PMOS/NMOS) and the interface between the higher current / voltage requirements. And it is widely used in computers, industrial and consumer products in the lamps, relays, hammers or other similar load. The stepper motor driver circuit is shown in Figure IV.

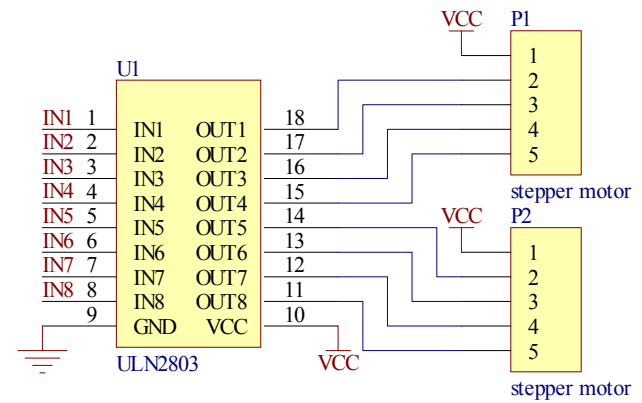

FIGURE IV. THE STEPPER MOTOR DRIVER CIRCUIT

\section{Clock Module}

Because the sun angle tracking method requires the exact time of the local time, so the need to use the clock circuit. If the use of single-chip timing, a long time will cause greater error, the need to use a serial real-time clock chip.

The system uses serial clock chip DS1302 as the core of the external clock circuit.DS1302, although not taken photoelectric isolation but because of read and write by the timing control, and has a write-protect bit, anti-jamming effect, while small size, less connection, only one external $32.768 \mathrm{~Hz}$ crystal, the use of flexible [7].The DS1302 real-time clock counts the number of seconds, minutes, hours, days, weeks, months, and years with leap year compensation, and has $31 *$ 8RAM for saving useful data. Read / write for clock or RAM data with single byte or multi-byte (also known as pulse mode) data transfer [8].Dual power supply (main and backup power) power supply. The clock circuit is shown in Figure V.

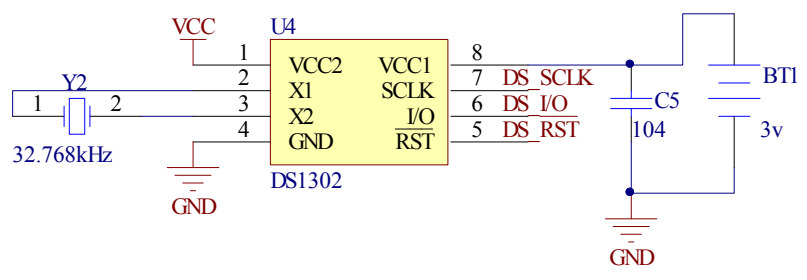

FIGURE V. THE CLOCK CIRCUIT

\section{SOFTWARE DESIGN}

\section{E. The Main Program}

This is the order of the main program: First of all to determine the day and night, if the night system to start the interrupt routine, the system enters the wait state. Otherwise, 
to enter the weather detection process. Cloudy day, the system uses the sun angle tracking mode; sunny day, the use of photoelectric tracking mode. The main program flow chart is shown in Figure VI.

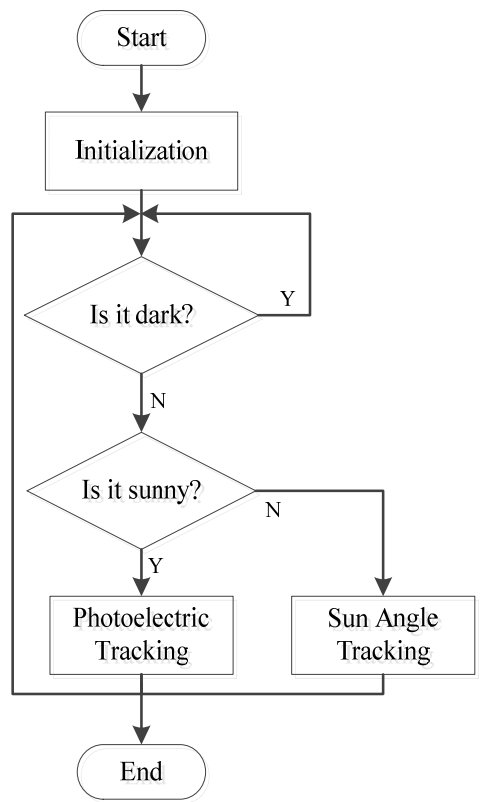

FIGURE VI. THE MAIN PROGRAM FLOW CHART

\section{F. Photoelectric Tracking Subroutine}

After entering the photoelectric detection tracking mode, the first acquisition of $\mathrm{A}, \mathrm{B}, \mathrm{C}, \mathrm{D}$ these 4 photosensitive resistance at both ends of the voltage value, after the $\mathrm{A} / \mathrm{D}$ conversion, the comparison of $\mathrm{A}$ and $\mathrm{C}, \mathrm{B}$ and $\mathrm{D}$ voltage values at both ends. On the $\mathrm{A}$ and $\mathrm{C}$ these two photosensitive resistance, that is, the left and right of the two photosensitive resistors, when the light intensity of the left photosensitive resistance is stronger than the light intensity of the right photosensitive resistor, namely, the voltage across the left photosensitive resistor is lower than the voltage across the right photosensitive resistor. The level of the stepper motor to the left until the left and right photosensitive resistors across the voltage difference is less than 0.2V.B and D in the same way, when the light intensity of the upper photosensitive resistance is stronger than the light intensity of the lower photosensitive resistor, namely, the voltage across the upper photosensitive resistor is lower than the voltage across the lower photosensitive resistor. The pitch of the stepper motor to the up until the upper and lower photosensitive resistors across the voltage difference is less than $0.2 \mathrm{~V}$. By default when the left and right, upper and lower, the voltage of the two ends of the photosensitive resistors is less than $0.2 \mathrm{~V}$, the sunlight is perpendicular to the solar panels. The Photoelectric tracking subroutine flow chart is shown in Figure VII.

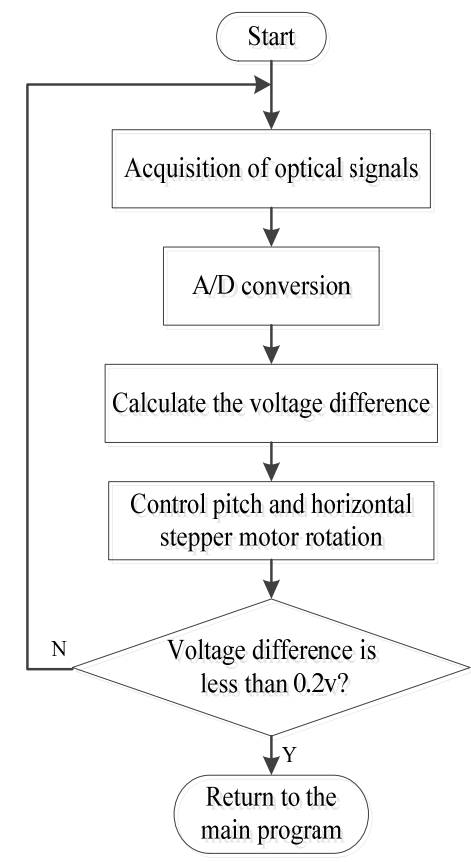

FIGURE VII. THE PHOTOELECTRIC TRACKING SUBROUTINE FLOW CHART

\section{G. Sun Angle Tracking Subroutine}

After entering the solar angle tracking mode, first read the DS1302 time, and calculated the solar altitude and the solar azimuth value by this time. SCM control stepper motor rotation, to achieve the sun angle tracking. The sun angle tracking subroutine flow chart is shown in Figure VIII.

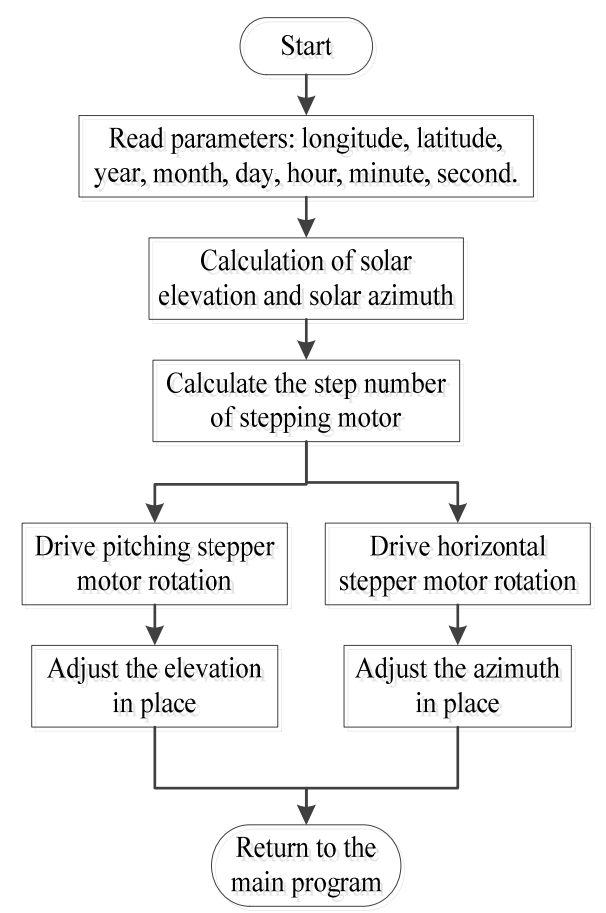

FIGURE VIII. THE SUN ANGLE TRACKING SUBROUTINE FLOW CHART 


\section{EXPERIMENTAL RESULTS ANALYSIS}

Two aspects of experimental testing are done in this paper. First, the test system comes with the program to calculate the accuracy of the sun position; Second, in the photoelectric detection tracking mode, whether the solar panel power is increased.

First, The data of this paper is calculated by using the solar position calculation formula in Visual $\mathrm{C}++$ and calculated by the program. The calculated value of the RiSuo calendar is taken as the standard value. The solar position parameters were calculated on May 15, 2016 in Shenyang City, Liaoning Province $\left(123^{\circ} 25^{\prime} \mathrm{E}, 41^{\circ} 48^{\prime} \mathrm{N}\right)$. The comparison with the standard values is shown in Table I.

\section{TABLE I. THE COMPARISON WITH THE STANDARD VALUES}

\begin{tabular}{|c|c|c|c|c|}
\hline \multicolumn{5}{|c|}{ Local time:2016.5.15 Local location: $123^{\circ} 25^{\prime} \mathrm{E}, 4^{\circ} 48^{\prime} \mathrm{N}$} \\
\hline Time & \multicolumn{2}{|c|}{ Standard value } & \multicolumn{2}{|c|}{ Calculated value } \\
\hline $8: 00$ & $37^{\circ} 44^{\prime}$ & $-81^{\circ} 48^{\prime}$ & $37^{\circ} 18^{\prime}$ & $-81^{\circ} 86^{\prime}$ \\
\hline 9:00 & $48^{\circ} 33^{\prime}$ & $-69^{\circ} 09^{\prime}$ & $48^{\circ} 10^{\prime}$ & $-69^{\circ} 50^{\prime}$ \\
\hline $10: 00$ & $58^{\circ} 18^{\prime}$ & $-51^{\circ} 40^{\prime}$ & $58^{\circ} 04^{\prime}$ & $-51^{\circ} 50^{\prime}$ \\
\hline 11:00 & $65^{\circ} 20^{\prime}$ & $-25^{\circ} 13^{\prime}$ & $65^{\circ} 41^{\prime}$ & $-27^{\circ} 57^{\prime}$ \\
\hline $12: 00$ & $66^{\circ} 52^{\prime}$ & $10^{\circ} 04^{\prime}$ & $66^{\circ} 38^{\prime}$ & $10^{\circ} 01^{\prime}$ \\
\hline $12: 30$ & $65^{\circ} 05^{\prime}$ & $27^{\circ} 00^{\prime}$ & $65^{\circ} 43^{\prime}$ & $27^{\circ} 43^{\prime}$ \\
\hline 13:00 & $61^{\circ} 56^{\prime}$ & $41^{\circ} 18^{\prime}$ & $61^{\circ} 70^{\prime}$ & $41^{\circ} 51^{\prime}$ \\
\hline 14:00 & $53^{\circ} 07^{\prime}$ & $62^{\circ} 15^{\prime}$ & $53^{\circ} 53^{\prime}$ & $62^{\circ} 58^{\prime}$ \\
\hline $15: 00$ & $42^{\circ} 39^{\prime}$ & $76^{\circ} 39^{\prime}$ & $42^{\circ} 44^{\prime}$ & $76^{\circ} 24^{\prime}$ \\
\hline $16: 00$ & $31^{\circ} 35^{\prime}$ & $87^{\circ} 50^{\prime}$ & $31^{\circ} 63^{\prime}$ & $87^{\circ} 45^{\prime}$ \\
\hline
\end{tabular}

After comparison with the calculation results of the RiSuo calendar, it can be seen that the error between the built-in function and the standard value of the system does not exceed $0.5^{\circ}$.

Because the design of the system comes with the calculation program and the RiSuo calendar used by the calculation of the same principle, as long as the calculation formula for programming without particularly large errors, the resulting calculation results will not appear too much error. The reason for the nuances in the calculation results is mainly due to the difference between the two functions or the calculation method.

Second: Because this work is small and light in weight, and solar panel is also small $(85.4 \mathrm{~mm} * 56.3 \mathrm{~mm})$, is not suitable for outdoor experiments, so this experiment using CEL-S500 xenon light source instead of the real sunlight, photoelectric Tracking experiment. Two solar panels were placed in the CEL-S500 xenon lamp light source, one for the fixed solar panels, one for the automatic tracking of solar panels. Keep the light intensity of the light source unchanged, change the direction of light irradiation (by loosening the outer casing of the ban screws to rotate), turn the steering head from $+60^{\circ} \sim-60^{\circ}, 15$ degrees per rotation using the voltage meter measuring the output voltage of two solar panels at both ends (open circuit voltage), the measurement results will be draw a table, as shown in Table II.
TABLE II. DATA COMPARISON TABLE

\begin{tabular}{|c|c|c|c|}
\hline \multicolumn{2}{|c|}{ Fixed Type } & \multicolumn{2}{c|}{ Automatic Type } \\
\hline Angle & Voltage & Angle & Voltage \\
\hline$+60^{\circ}$ & $1.19 \mathrm{v}$ & $+60^{\circ}$ & $5.89 \mathrm{v}$ \\
\hline$+45^{\circ}$ & $1.22 \mathrm{v}$ & $+45^{\circ}$ & $5.92 \mathrm{v}$ \\
\hline$+30^{\circ}$ & $5.92 \mathrm{v}$ & $+30^{\circ}$ & $5.94 \mathrm{v}$ \\
\hline$+15^{\circ}$ & $5.95 \mathrm{v}$ & $+15^{\circ}$ & $5.97 \mathrm{v}$ \\
\hline $0^{\circ}$ & $5.99 \mathrm{v}$ & $0^{\circ}$ & $5.99 \mathrm{v}$ \\
\hline$-15^{\circ}$ & $5.97 \mathrm{v}$ & $-15^{\circ}$ & $5.98 \mathrm{v}$ \\
\hline$-30^{\circ}$ & $5.94 \mathrm{v}$ & $-30^{\circ}$ & $5.96 \mathrm{v}$ \\
\hline$-45^{\circ}$ & $1.20 \mathrm{v}$ & $-45^{\circ}$ & $5.93 \mathrm{v}$ \\
\hline$-60^{\circ}$ & $1.21 \mathrm{v}$ & $-60^{\circ}$ & $5.88 \mathrm{v}$ \\
\hline
\end{tabular}

As can be seen from the table, the automatic open-circuit voltage is almost all around $5.9 \mathrm{~V}$, while the fixed only in the $+30^{\circ} \sim-30^{\circ}$ between the voltage maintained at $5.9 \mathrm{~V}$, beyond the range of voltage straight down, you can see the automatic tracking system with higher solar energy utilization.

\section{CONCLUSION}

This design adopts the method of photoelectric tracking and sun angle tracking combination, while using the two step motor of solar panels on the level and pitch control of two degrees of freedom, to achieve all-weather precise tracking of the sun. Experimental results show that the system has the characteristics of high tracking accuracy, low energy consumption, accurate data, strong applicability and so on. It improves the accuracy of the sun tracking, and reaches the goal of making full use of solar energy.

\section{REFERENCES}

[1] Geng Xin, and Lin Zhongda, "PLC design of intelligent solar automatic tracking system, 3rd ed., vol. 2.Industrial instrumentation and automation, 2010,pp. 30-33.

[2] Zhang Yongtao,Wang Huahua and Li Guangti, "Design of intelligent double precision solar automatic tracking system based on AT89S52,"1rd ed., vol. 4. Journal of Shandong Agricultural University, 2012, pp.143-147.

[3] Xiao Yuhua, and Xiong Hejin, "Design of dual axis solar tracker based on ATmega8," 3rd ed., vol. 18.Electronic design engineering, 2010, pp. 46-50.

[4] Han zhuqin,Niu Yuanwang, and li Yuhua, "Design of solar tracking system based on STC89C52,"vol. 2.Electronic quality,2016,pp. 31-34.

[5] Li Yongxia,LiZhan, and Liu Chang, "Solar panel automatic tracking system based on STC MCU," vol. 33.Computer application,2013,pp. 331-332.

[6] Li Haoshuai, and Wang Gao, "Design of photovoltaic power generation tracking system based on photoelectric detection technology," 1rd ed., vol. 21. J. Signals and systems,2014,pp. 29-33.

[7] Li Jie,Kong Hao, and Zhang Fei, "Application of dual axis tracking system in photovoltaic power station," 1rd ed., vol. 31. Automatic instrument,2016,pp. 57-62.

[8] Li Peng,Liao Jincheng, and Cai Lanlan, "Research on motion control law of two axis solar tracking system," 48rd ed., vol. 550.Research and development,2010,pp. 24-26. 